\title{
MEDIA VIDEO PROFILE SEBAGAI MEDIA PROMOSI DAN INFORMASI PADA SMK BINA AM MA'MUR
}

\author{
Desy Apriani ${ }^{1}$ \\ Haerul $^{2}$ \\ Yanuar Arif Febriana ${ }^{3}$ \\ Alumni STMIK Raharja Jurusan Sistem Informasi ${ }^{1}$, STMIK Raharja Jurusan Teknik Informatika ${ }^{2,3}$ \\ Jl. Jendral Sudirman No. 40, Modernland, Tangerang ${ }^{1,2,3}$ \\ Email:desy@raharja.info ${ }^{1)}$,haerul.haerul@raharja.info ${ }^{21}$,yanuar.arif@raharja.info
}

\begin{abstract}
ABSTRAK
Dengan berkembangnya teknologi informasi khususnya dibidang multimedia yang sedemikian pesat dan semakin lama bentuk media informasi lebih beragam sehingga instansi pendidikan lebih membanggakan. Media informasi dan promosi saat ini digunakan oleh SMK Bina Am' Makmur. Tujuan dari penelitian ini media audio visual menjadi media informasi dan promosi yang tepat, dengan mengendalikan pendengaran dan penglihatan dalam bentuk audio visual agar pesan yang di sampaikan dapat dimengerti oleh masyarakat luas. Permasalahan yang ada yaitu media yang digunakan oleh SMK Bina Am' Makmur masih menggunakan media cetak seperti spanduk, poster dan pamplet yang dirasa kurang begitu efektif dan efesien untuk menggunakan sekaligus mempromosikan instansi dengan sebaik mungkin Sehingga media audio visual dipilih menjadi media informasi dan promosi yang tepat, dengan mengendalikan pendengaran dan penglihatan dalam bentuk audio visual. Karena didalamnya terdapat proses penyampaian pesan atau cara memvisualisasikan. Sekaligus mendengarkan dan memperlihatkan isi pesan informasi kepada penerima dengan melalui media yang menunjangnya, sehingga perancangan media video profile yang menampilkan seluruh ruang lingkup, keunggulan, dan fasilitas yang dimiliki SMK Bina Am' Makmur, dapat menjadi solusi dalam pemecahan masalah pada media promosi dan informasinya. Dengan ini penulis membuat penelitian dengan judul "MEDIA VIDEO PROFILE SEBAGAI MEDIA PROMOSI DAN IINFORMASI PADA SMK BINA AM MA'MUR”.
\end{abstract}

Kata kunci : Promosi, Audio Visual, Video Profile.

\begin{abstract}
With the development of information technology in particular in the field of multimedia in such rapid and the longer forms of media more diverse so that educational agencies to demand a more boasts information from various media. Media information and promotions that are currently used by CMS Bina Am ' prosperous. The purpose of this research was chosen as the audio visual media media information and proper promotion, by controlling hearing and vision in the form of audio visual in order to convey messages can be understood by the public at large. Existing problems, namely the medium used by the CMS Community still Prospers Am ' in the form of print media such as banners, posters and pamplet are considered less effective and efficient to use while simultaneously promoting the institutions with the best possible audio visual media so that it is selected into a medium of information and promotion of the right, by controlling hearing and vision in the form of audio visual. Because therein lies the message delivery process or how to visualize. At the same time listening and showing the contents of the message to the recipient with information through media menunjangnya, so the design of video media profile that displays the entire scope, advantages and facilities belonging to SMK Bina Am' prosperous, can be a solution in solving problems in media promotion and information. With this study the author makes with the title of "VIDEO MEDIA PROFILE AS a MEDIA PROMOTION and IINFORMASI on CMS BINA AM MA'MUR".
\end{abstract}

Keywords: promotion, Audio Visual, Video Profile. 


\section{PENDAHULUAN}

Pendidikan merupakan salah satu manifestasi kebudayaan manusia yang dinamis dan syarat perkembangan, karena itu perubahan atau perkembangan pendidikan merupakan hal yang seharusnya terjadi sejalan dengan perubahan budaya kehidupan. Perubahan dalam arti perbaikan pendidikan pada semua tingkat perlu terus menerus dilakukan sebagai antisipasi kepentingan masa depan. Pemikiran ini mengandung konsekuensi bahwa penyempurnaan atau perbaikan pendidikan menengah kejuruan untuk mengantisipasi tantangan masa depan perlu terus-menerus dilakukan, diselaraskan dengan perkembangan kebutuhan dunia usaha atau dunia industri, perkembangan dunia kerja, serta perkembangan ilmu pengetahuan teknologi dan seni.

Salah satu bidang yang dapat dipadukan dengan adanya perkembangan bidang multimedia dapat ditemui dalam dunia periklanan khususnya dalam dunia pendidikan. Perkembangan teknologi informasi khususnya teknologi multimedia dewasa ini telah berkembang semakin pesat sehingga membuat kehidupan manusia sekarang ini menjadi sedemikian mudah dan menyenangkan. Permasalahan yang sering terjadi adalah sarana dalam mempromosikan sekolahsekolah yang ada di Indonesia khususnya di Tangerang masih sangat sedikit. Diperlukan trobosan baru, dan dalam hal ini dapat diambil sebagai contoh adalah video profile yang sering kali digunakan sebagai media perkenalan dan promosi sekolah-sekolah di Indonesia. Terdapat berbagai jenis iklan dan video profile yang sering diproduksi, mulai dari yang seluruhnya ditokohkan dan diperankan oleh manusia hingga yang menggunakan animasi 3D atau kartun yang diperankan oleh tokoh-tokoh berupa karakter yang dibuat sedemikian rupa sehingga mempunyai sifat dan tingkah laku layaknya manusia.
Pada tanggal 14 Januari 2006 Yayasan Bina Am Ma'mur didirikan oleh pasangan Suami Istri KH. Astama Ambun Sarkawi (77 th) dan $\mathrm{Hj}$. Murtafi'ah bin H. Taham (70 th). Perjuangan keduanya dalam bidang pendidikan mendapat dukungan penuh dari keluarga. Sembilan orang anak turut serta mepercepat dibuatnya payung hukum. Maka melalui Notaris Harsono SH keluarlah Akte Notaris No. 84 Tanggal 27 Januari 2007 yang mengesahkan berdirinya Yayasan Bina Am Ma'mur

Dengan adanya kebutuhan diatas, maka penulis akan mencoba memberikan solusi dengan membuat video profile sebagai media informasi berbasis multimedia pada SMK Bina Am' Makmur Cikupa yang akan memberikan kemudahan dan kebutuhan informasi yang lebih cepat, tepat dan akurat, sekolah tersebut membutuhkan media informasi dan promosi yang menarik untuk memperkenalkan seluruh calon siswa dan siswi yang akan mendaftar di SMK Bina Am' Makmur Cikupa dan diharapkan melalui perancangan media video profile ini dapat menambah peningkatan calon siswa dan siswi SMK Bina Am' Makmur Cikupa.

\section{RUMUSAN MASALAH}

Saat ini perkembangan media promosi berkembang sangat pesat. Media yang banyak digunakan saat ini dapat berupa media komunikasi visual maupun audio visual. Banyak sekolah-sekolah yang sudah menggunakan media audio visual sebagai salah satu cara untuk mempromosikan suatu instansi pendidikan. Media audio visual merupakan media yang paling mudah dipahami dan dimengerti oleh calon Siswa dan siswi SMK Bina Am' Makmur Cikupa, karena di dalamnya terdapat unsur - unsur yang menarik, baik dari 
segi pengambilan gambar maupun editing.

Permasalahan yang melatar belakangi penelitian ini adalah kurangnya media promosi yang digunakan oleh SMK Bina Am' Makmur Cikupa dalam mempromosikan secara keseluruhan apa yang ada dan disediakan oleh SMK Bina Am' Makmur Cikupa, karena dalam melaksanakan suatu promosi masih menggunakan sebuah media promosi berupa media cetak, maka dari itu dibuatlah suatu teknik promosi baru untuk SMK Bina Am' Makmur Cikupa dengan menggunakan video profile.

\section{LANDASAN TEORI}

\section{Pengertian Perancangan}

Perancangan adalah suatu kegiatan membuat desain teknis berdasarkan evaluasi yang telah dilakukan pada kegiatan analisis. Perancangan merupakan wujud visual yang dihasilkan dari bentuk-bentuk kreatif yang telah direncanakan. Langkah awal dalam perancangan desain bermula dari hal-hal yang tidak teratur berupa gagasan atau ide-ide kemudian melalui proses penggarapan dan pengelolaan akan menghasilkan hal-hal yang teratur, sehingga hal-hal yang sudah teratur bisa memenuhi fungsi dan kegunaan secara baik $^{[10]}$.

Perancangan adalah tahap pembuatan spesifikasi mengenai arsitektur program, gaya, tampilan, dan kebutuhan material atau bahan untuk program. Tahap ini biasanya menggunakan storyboard untuk menggambarkan deskripsi tiap scene lain dan bagan alir (flowchart) untuk menggambarkan aliran dari satu scene ke scene lain ${ }^{[4]}$.

Perancangan adalah wujud visual yang dihasilkan dari bentuk-bentuk kreatif yang telah direncanakan. Langkah awal dalam perancangan desain bermula dari hal-hal yang tidak teratur berupa gagasan atau ide-ide kemudian melalui proses penggarapan dan pengelolaan akan menghasilkan hal-hal yang teratur, sehingga hal-hal yang sudah teratur bisa memenuhi fungsi dan kegunaan secara baik.

\section{Konsep Dasar Media}

"Media adalah segala bentuk yang digunakan untuk menyalurkan informasi. Pengertian media yang diberikan AECT (Association for education communication and tecnology) ini menunjukkan bahwa istilah "media" memiliki makna yang sangat umum ${ }^{[5] " .}$

\section{Konsep Dasar Video Pengertian Video}

Video merupakan gabungan gambargambar mati yang dibaca berurutan dalam suatu waktu dengan kecepatan tertentu. Gambar-gambar yang digabung tersebut dinamakan frame dan kecepatan pembacaan gambar disebut dengan frame rate, dengan satuan fps (frame per second $)^{[1]}$.

\section{Konsep Dasar Video Profile}

Video profile perusahaan (corporate profile) merupakan video yang diproduksi untuk keperluan tertentu, misalnya memperkenalkan suatu perusahaan tertentu untuk disebarluaskan ke publik, selain itu sering dipakai sebagai sarana pendukung dalam suatu presentasi perusahaan atau kelompok tertentu $^{[11]}$.

Video profile adalah sebuah gambaran infomasi tentang riwayat seorang atau sebuah instansi perusahaan yang telah mencapai suatu pencapaian kesuksesan dalam hal produksi atau hasil karya yang telah dihasilkan dan diterima di kalangan masyarakat umum. Informasi tersebut disebarkan berbentuk audio visual atau video $^{[7]}$.

\section{Konsep Dasar Promosi}

Promosi merupakan salah satu penentu keberhasilan suatu program pemasaran. Pentingnya promosi dapat digambarkan lewat perumpamaan bahwa pemasaran 
tanpa promosi dapat diibaratkan seorang pria berkaca mata hitam yang dari tempat gelap pada malam kelam mengedipkan matanya pada seorang gadis di kejauhan.

\section{Konsep Dasar Informasi}

Informasi adalah data yang telah diolah menjadi sebuah bentuk yang lebih berarti bagi penerimanya, dan bermanfaat dalam mengambil sebuah keputusan ${ }^{[8]}$.

\section{Tahapan Produksi}

\section{Pra Produksi}

Pra produksi adalah sebuah proses produksi yang merupakan tahapan awal dari seluruh kegiatan yang akan datang atau juga disebut sebagai tahapan perencanaan.

\section{Konsep Dasar Multimedia Audio Visual and Broadcasting Pengertian Multimedia}

Multimedia merupakan kombinasi teks, seni, suara, gambar, animasi, dan video yang disampaikan dengan komputer atau dimanipulasi secara digital dan dapat disampaikan atau dikontrol secara interaktif $^{[9]}$.

\section{Pengertian Audio Visual}

Audio visual merupakan gabungan dari dua kata yaitu audio yang berarti suara dan visual yang berarti gambar, atau dengan kata lain menjelaskan, "Audio Visual adalah alat peraga yang dapat dilihat dan didengar dalam hal ini gambar yang bergerak menimbulkan suara ${ }^{[2]}$."

\section{Pengertian Sinopsis}

Sinopsis adalah ringkasan cerita media periklanan atau film, merupakan bentuk atau pendekatan dari sebuah periklanan atau film dengan tetap memperhatikan unsur-unsur pencerminan dari sebuah periklanan atau film tersebut ${ }^{[6]}$.

\section{Pengertian Storyboard}

sebuah teknik shooting management. Disini dibuat daftar pengambilan gambar pada setiap adegan, dan divisualisasikan dalam bentuk sketsa gambar atau storyboard jika diperlukan.

\section{Pengertian Broadcasting}

Broadcasting adalah distribusi audio visual atau video yang mengirimkan sinyal program untuk penonton.

\section{PROGRAM APLIKASI PENUNJANG VIDEO PROFILE}

\section{Adobe Prmiere Pro CS3}

Adobe Premiere merupakan program untuk menyunting dan mendesain film dan video, disamping juga dapat digunakan untuk membuat desain iklan ${ }^{[3]}$.

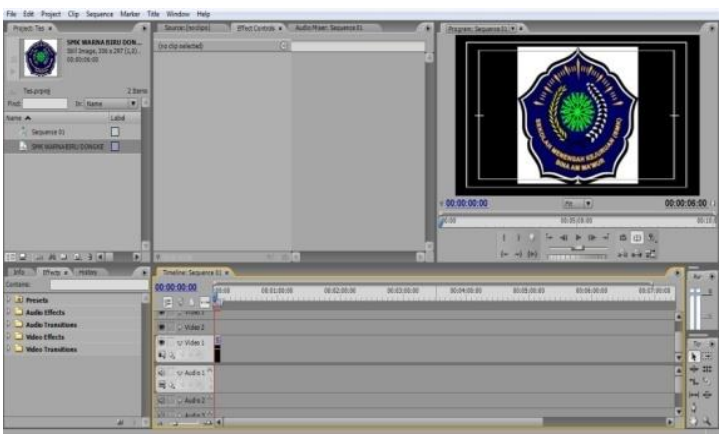

Gambar 1. Adobe premier

\section{Corel Video Studio X5}

Definisi tugas berat video high editing software yang memungkinkan mengimpor pengguna, mengedit, membuat, ekspor dan berbagi standar mereka sendiri dan video definisi tinggi.

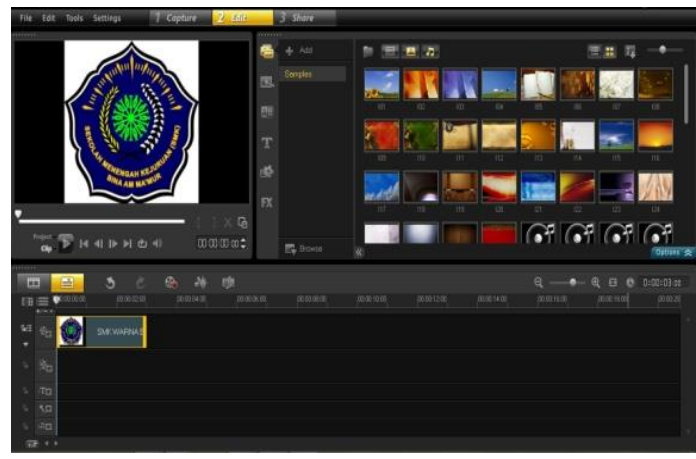

Gambar 2. Corel Video X5

\section{Adobe Photoshop CS2}

suatu perangkat lunak canggih yang dapat Anda gunakan untuk membuat, menyunting dan memanipulasi tampilan 
termasuk mengoreksi warna dan memberi efek tampilan atas sebuah gambar atau photo, hasil dari program ini merupakan sebuah gambar / image, di dalam komputer grafis terbagi menjadi 2 kelompok yaitu gambar Bitmap dan gambar Vektor.

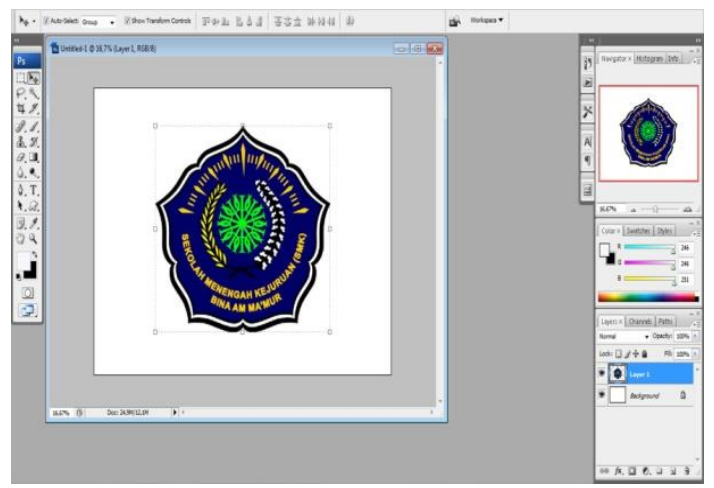

Gambar 3. Adobe Photoshop

\section{LITERATURE REVIEW}

1. Penerapan Teknologi Multimedia Dalam Pembuatan Company Profile Dan Sarana Promosi SLTPN 2 Prambanan, Klaten adalah salah satu judul tugas akhir yang di buat oleh Muhammad Firdaus, Agung Setya Nugraha, Anjang Bawono, Tiar Pratomo selaku mahasiwa STMIK AMIKOM Yogyakarta. Penelitian ini menjelasan tentang Pembuatan Company Profile Dan Sarana Promosi SLTPN 2 Klaten.

2. Pengembangan media video pembelajaran sains bermuatan nilai ketuhanan dan kecintaan terhadap lingkungan, Lampung adalah salah satu judul Skripsi yang dibuat oleh Didi Rahmadi selaku mahasiswa Universitas Lampung. Penelitian ini menjelaskan tentang pembelajaran sains yang mengalami kesulitan dalam mempublikasikan kecintaan terhadap lingkungan, maka dibuatlah solusi yaitu sebuah media video pembelajaran sains bermuatan nilai ketuhanan dan kecintaan terhadap lingkungan.

3. Pengaruh Multimedia Pinnacle Studio Terhadap Hasil Belajar Peserta Didik Pada Pembelajaran Ekonomi Di SMA Negeri 10 Palembang, Palembang adalah salah satu judul Skripsi yang dibuat oleh Revo Ade Cahyo, Prof. Dr. H. M. Djahir Basir, Deskoni selaku mahasiswa Universitas Palembang. Penelitian ini menjelaskan tentang pembelajaran ekonomi SMAN 10 palembang mengalami kesulitan dalam memplubikasikan Multimedia Pinnacle Studio Terhadap Hasil Belajar Peserta Didik Pada Pembelajaran Ekonomi Di SMA Negeri 10 Palembang.

\section{METODE PENELITIAN}

Agar perolehan data lebih akurat dipenelitian ini, terdapat beberapa penerapan metode, yaitu : (1). Metode Analisa Permasalahan. Metode ini merupakan suatu metode yang digunakan untuk menentukan topik permasalahan penelitian, dalam hal ini dilakukan dengan bentuk interview yang menanyakan tentang permasalahan permasalahan yang terdapat pada lembaga instansi yang terkait dengan proses mempromosikan sekolah; (2). Metode Pengumpulan Data yaitu cara untuk mendapatkan data dengan jalan pengamatan secara langsung ke lokasi (Observasi), Interview ataupun dari kajian pustaka; (3).Analisa Data berupa pengolahan data atau informasi yang diangkat dari hasil perancangan dan penelitian terhadap video profile SMK At-Thahirin 2 Ciledug kota Tangerang yang akan dianalisa dan diolah menggunakan software atau aplikasi program yang mendukung dalam proses perancangan; (4).Metode Analisa Perancangan, dalam produksi 
Perancangan Video Profile Sebagai Media Promosi pada SMK Bina Am' Makmur Cikupa dipergunakan aplikasiaplikasi penunjang diantaranya aplikasi Corel Video Studio ProX5 sebagai pengolah video setelah dilakukan produksi, sedangkan aplikasi Adobe After Effects CS 5dipergunakan untuk pembuatan animasi bumper saat opening maupun closing; (5). Konsep Dasar Media berisi mengenai Preproduction, Production, dan Postproduction.

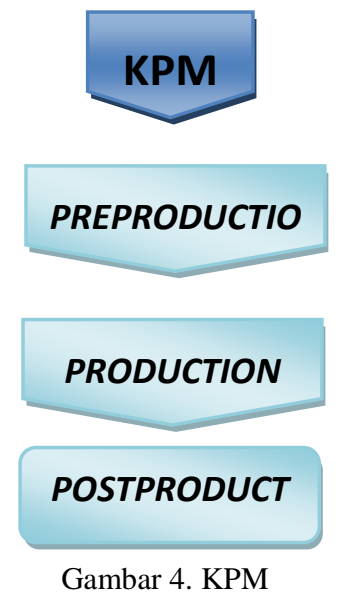

\section{Preproduction}

Untuk Preproduction adalah step atau langkah dimana dimulainya ide, perencanaan dan persiapan dari Konsep Produksi MAVIB. Ada tujuh langkah Preproduction dalam Konsep Produksi MAVIB, dimulai dari Ide yang dituangkan secara sistematis, lalu diikuti dengan pembuatan sinopsis, Script Writting dan Storyboard.

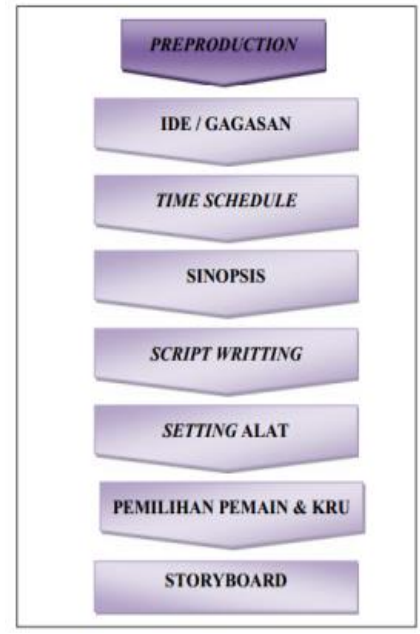

Gambar 5. Preproduction

\section{Storyboard}

Storyboard adalah rancangan berupa sket gambar yang dilengkapi dengan petunjuk atau catatan pengambilan gambar untuk kebutuhan shooting. Selama proses pra produksi, perencanaan yang berhubungan dengan visualiasasi yang akan dibuat membutuhkan Storyboard sebagai media bantuannya.

Scene 1
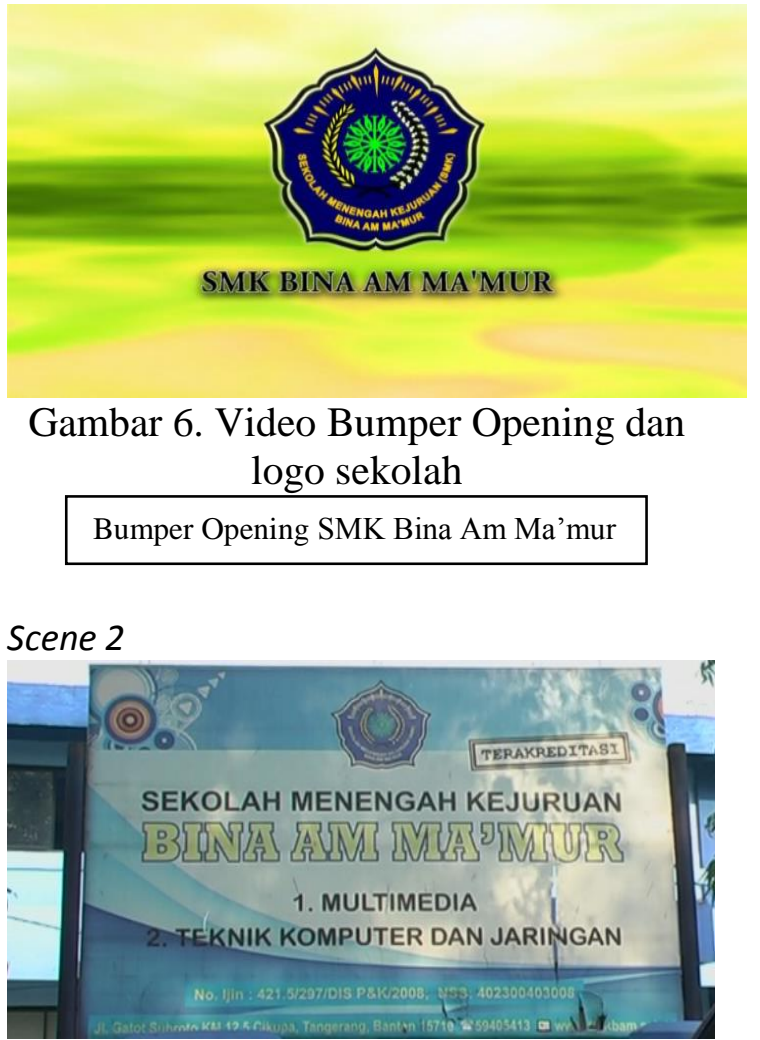

Gambar 7. Video Papan Nama Sekolah SMK Bina Am Ma'mur

Medium Closeup (MC) / EXT

Menggambarkan Papan Sekolah SMK Bina Am Ma'mur

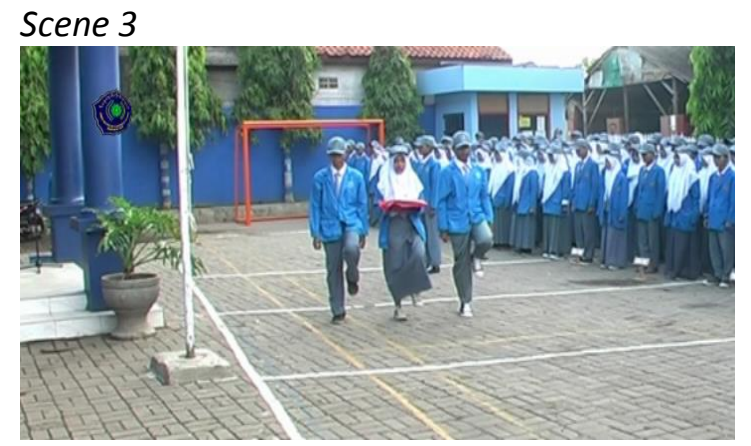

Gambar 8. Upacara SMK Bina Am Ma'mur 


\section{Full Shoot (FS) / EXT}

Menggambarkan Upacara SMK Bina Am Ma'mur

Scene 4

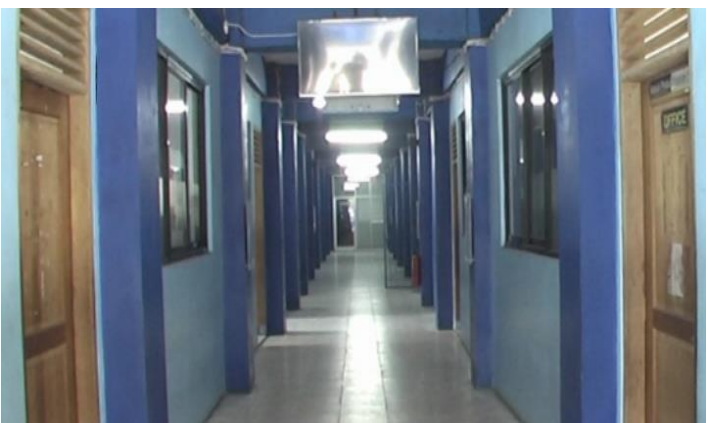

Igambar 9. Video lorong SMK Bina Am

Ma'mur

Long Shoot (LS) / INT

Menggambarkan Lorong gedung sekolah SMK Bina Am Ma'mur

Scene 5

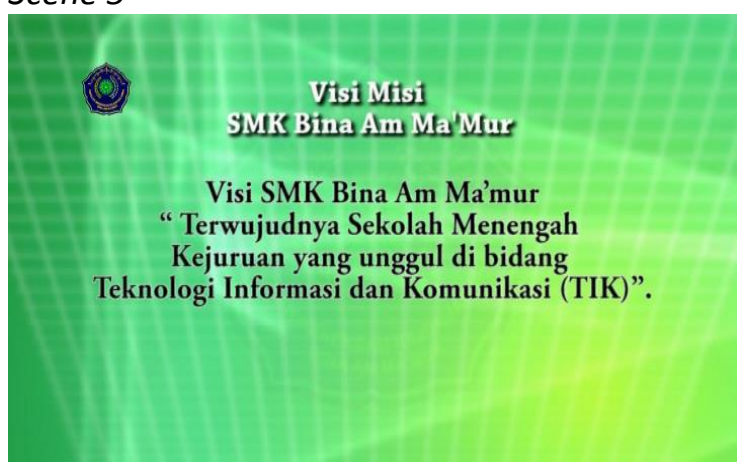

Gambar 10. Visi dan Misi

Menggambarkan Visi Misi SMK Bina Am Ma'mur

Scene 6

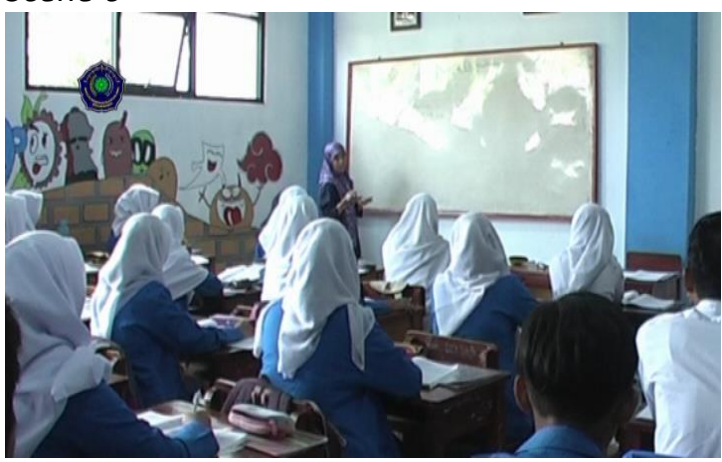

Gambar 11. Video belajar mengajar di kelas SMK Bina Am Ma'mur

Full Shoot (FS) / EXT

Menggambarkan Siswa dan siswi sedang belaiar di ruang kelas
Scene 7

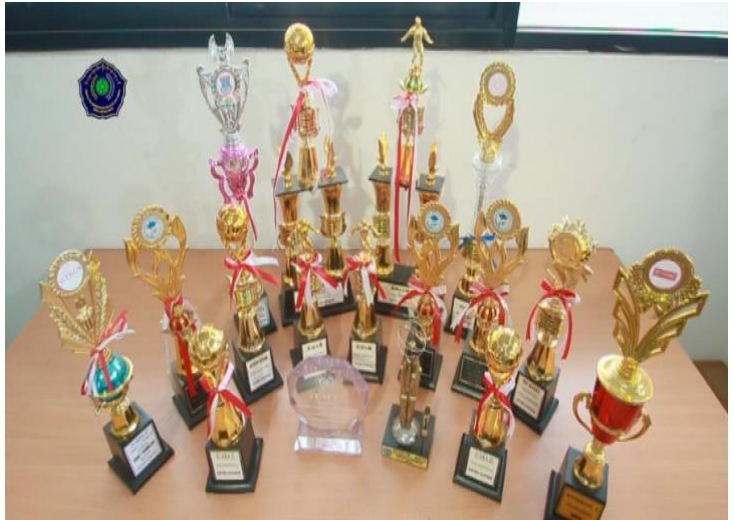

Gambar 12. Video Piala SMK Bina Am Ma'mur

\section{Medium Close Up (MCU) / INT \\ Menggambarkan Prestasi yang diraih oleh siswa siswi}

Scene 8

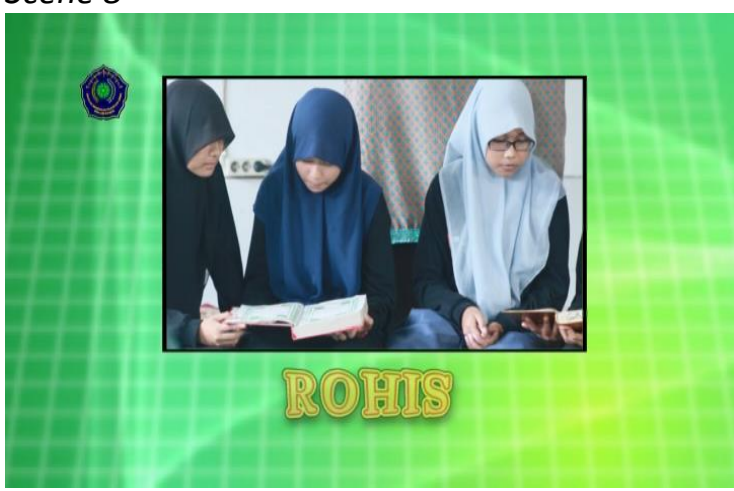

Gambar 13. Video Ekskul Rohis

Medium Close Up (MCU) / INT

Menggambarkan Ekstrakulikuler Rohis SMK Bina Am Ma'mur

Scene 9

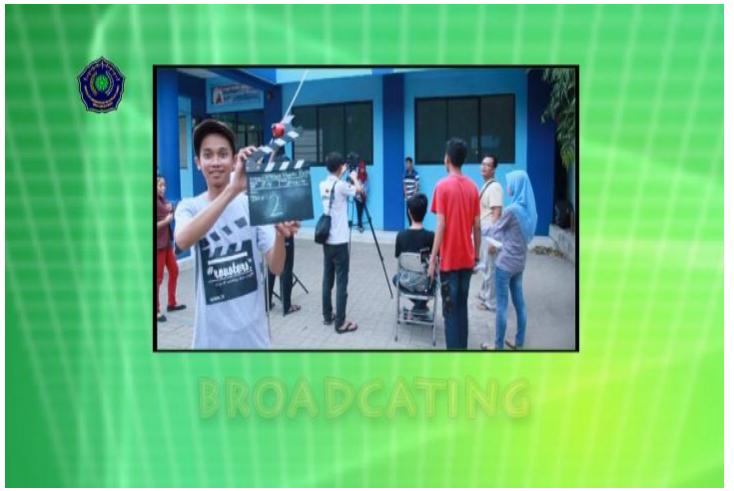

Gambar 14. Video Ekskul Broadcasting

Full Shoot (FS) / EXT

Menggambarkan Ekstrakulikuler Broadcasting SMK Bina Am Ma'mur 
Scene 10

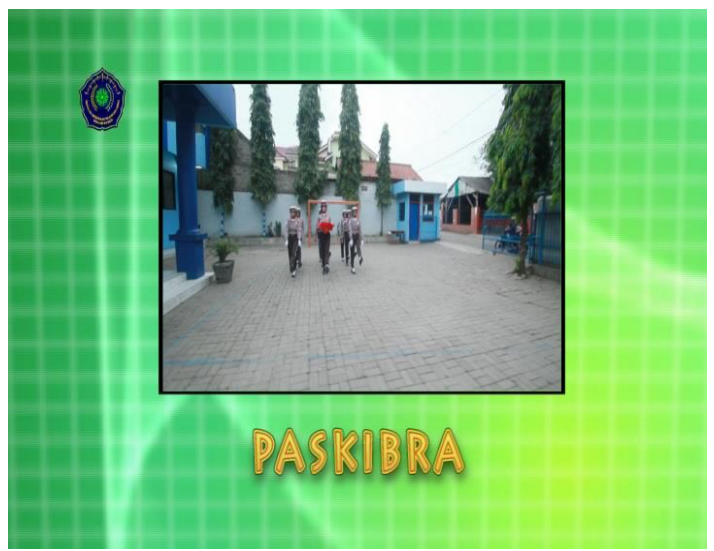

Gambar 15. Video Ekskul Paskibra

\section{Medium Long Shoot (MLS) / EXT \\ Menggambarkan Ekstrakulikuler \\ Paskibraka SMK Bina Am Ma'mur}

\section{Scene 11}

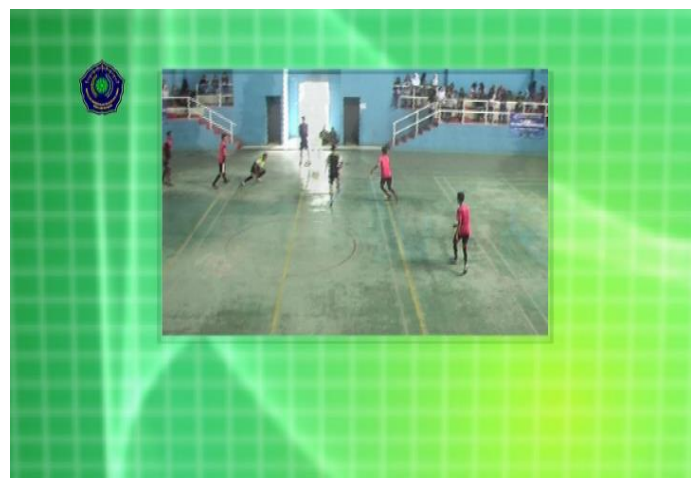

Gambar 16. Video Ekskul Futsal Pria

\section{Full Shoot (FS) / INT}

Menggambarkan Ekstrakulikuler

Futsal Pria SMK Bina Am Ma'mur

\section{Scene 12}

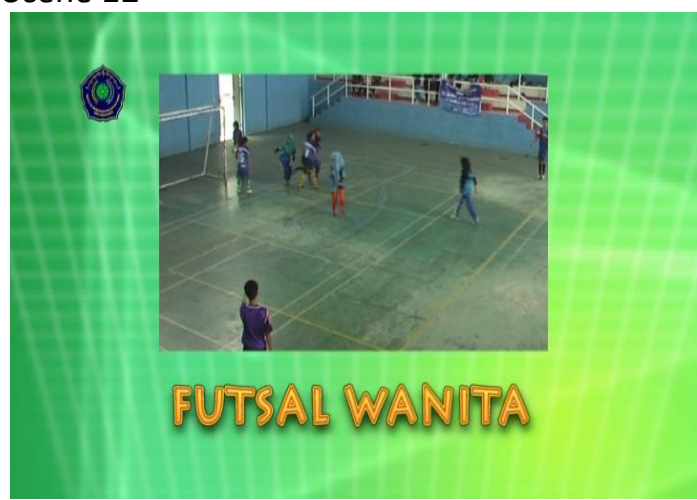

\section{Gambar 17. Video Futsal Wanita}

\section{Full Shoot (FS) / INT}

Menggambarkan Ekstrakulikuler

Futsal Pria SMK Bina Am Ma'mur
Scene 13

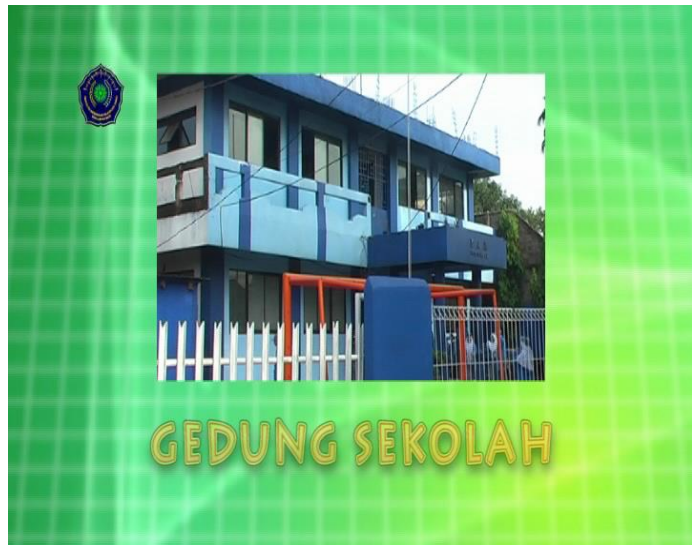

Gambar 18.Video Sarana dan Prasarana Gedung Sekolah

Full Shoot (FS) / EXT

Menggambarkan Gedung sekolah SMK Bina Am Ma'mur

Scene 14

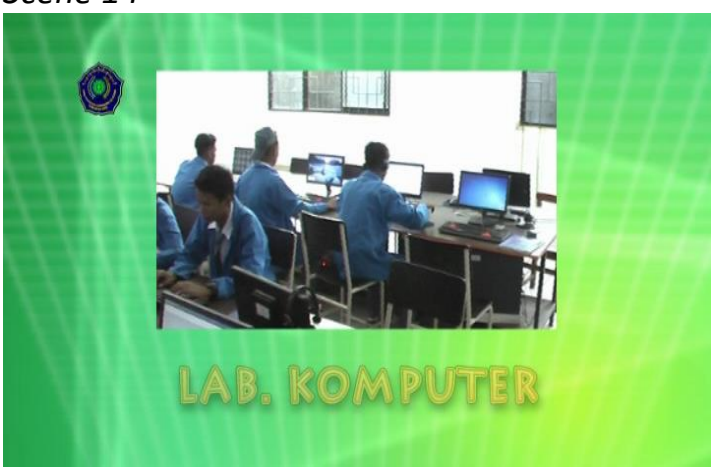

Gambar 19. Video Lab. Komputer

Medium Close Up (MCU) / INT

Menggambarkan Lab. Komputer SMK Bina Am Ma'mur

Scene 15

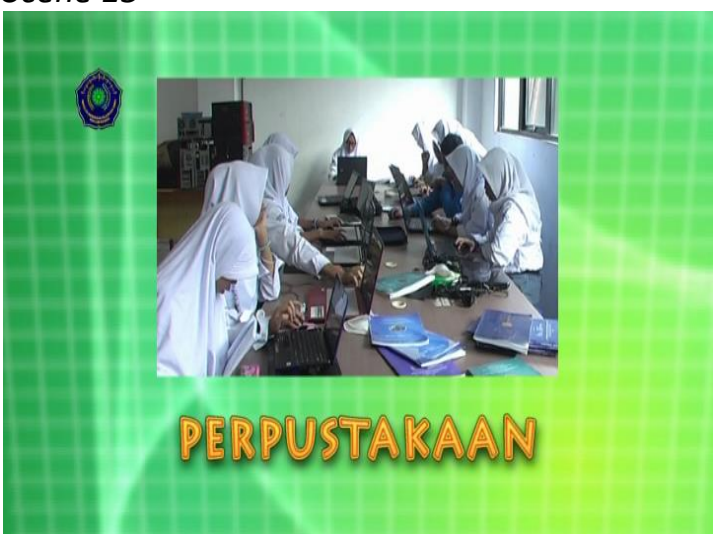

Gambar 20. Video Perpustakaan

Medium Close Up (MCU) / INT

Menggambarkan Perpustakaan SMK Bina Am Ma'mur 
Scene 16

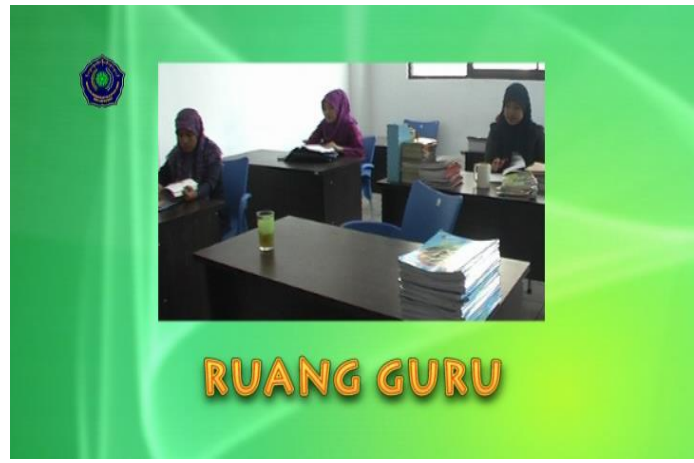

Gambar 21. Video Ruang guru

Medium Close Up (MCU) / INT Menggambarkan Ruangan Guru SMK Bina Am Ma'mur

\section{Scene 17}

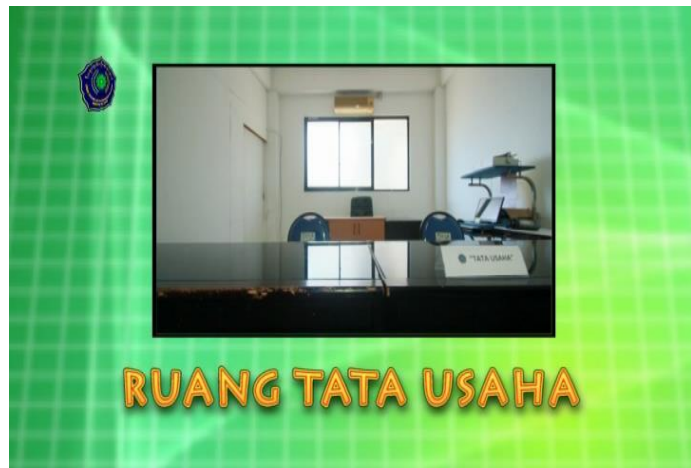

Gambar 22. Video Ruang Tata Usaha/Close Up

\section{Close Up (CU) / INT \\ Menggambarkan Ruangan Tata Usaha SMK Bina Am Ma'mur}

\section{Scene 18}

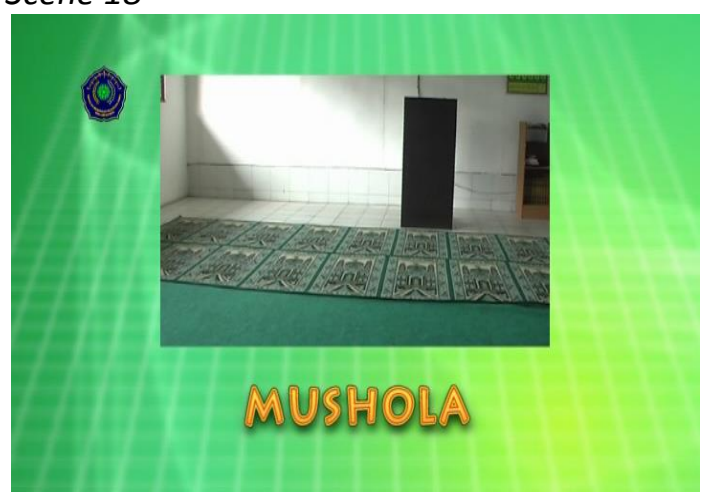

Gambar 23. Video Mushola

Medium Close Up (MCU) / INT Menggambarkan Ruangan Musholah SMK Bina Am Ma'mur
Scene 19

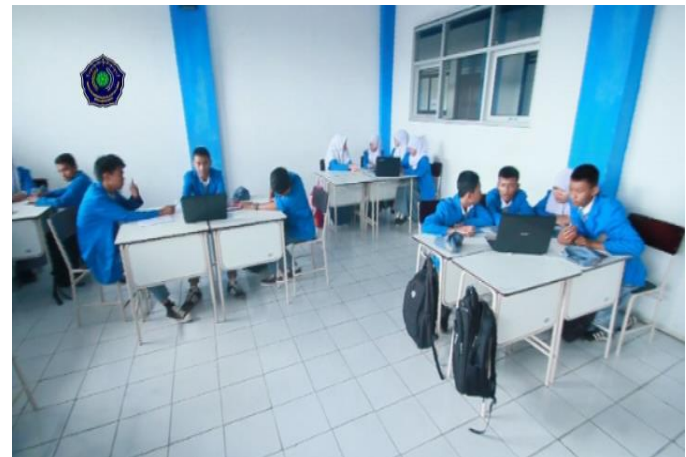

Gambar 24. Video kegiatan belajar mengajar di kelas SMK Bina Am

Ma'mur

Medium Close Up (MCU) / INT

Menggambarkan Ruangan Kelas Belajar siswa dan siswi SMK Bina Am Ma'mur

Scene 20

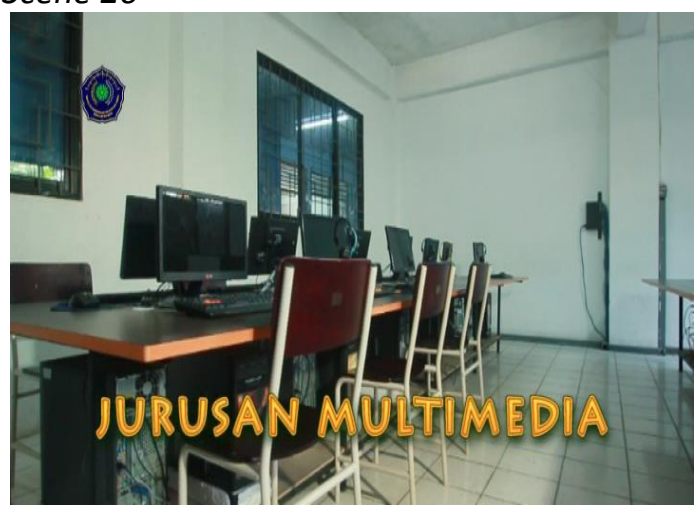

Gambar 25. Video Jurusan Multimedia SMK Bina Am Ma'mur

Full Shoot (FS) / INT

Menggambarkan Ruangan Kelas Praktek Multimedia SMK Bina Am Ma'mur

\section{Scene 21}

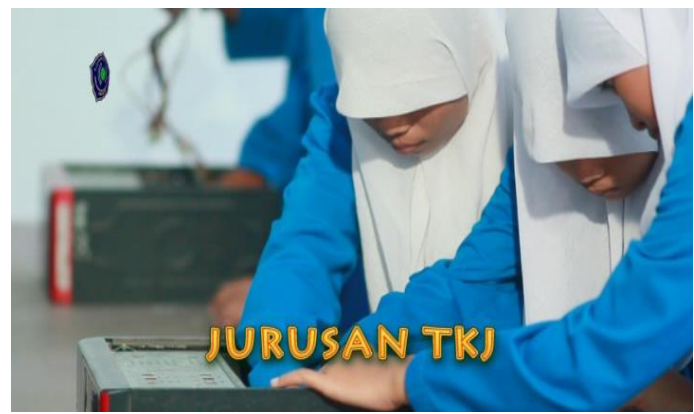

Gambar 26. Video Jurusan TKJ SMK Bina Am Ma'mur

Close Up (CU) / INT

Menggambarkan Ruangan Kelas Praktek TKJ SMK Bina Am Ma'mur 
Scene 22

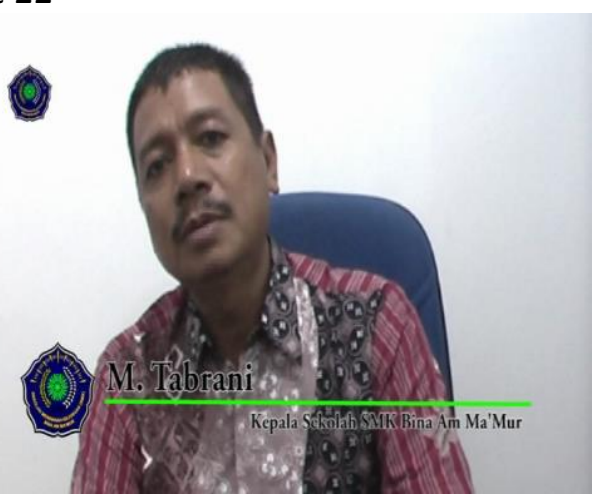

Gambar 27. Video Wawancara kepala sekolah SMK Bina Am Ma'mur/Medium Close Up

\section{Medium Close Up (MCU) / INT \\ Menggambarkan Wawancara kepala sekolah SMK Bina Am Ma'mur}

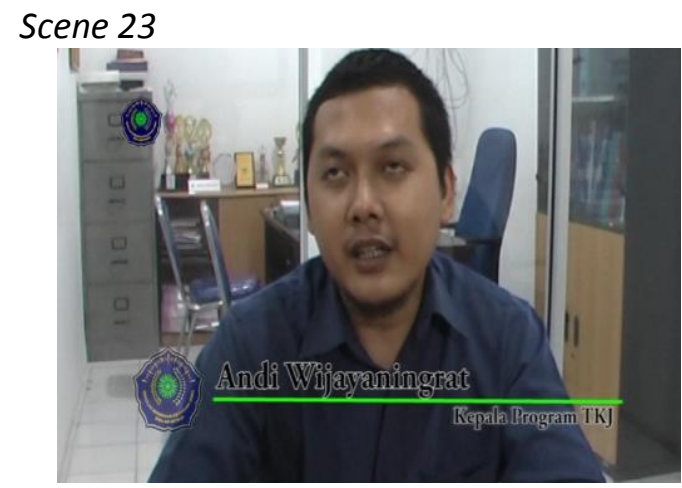

Gambar 28. Video Wawancara guru SMK Bina Am Ma'mur

Medium Close Up (MCU) / INT

Menggambarkan Wawancara Guru SMK Bina Am Ma'mur

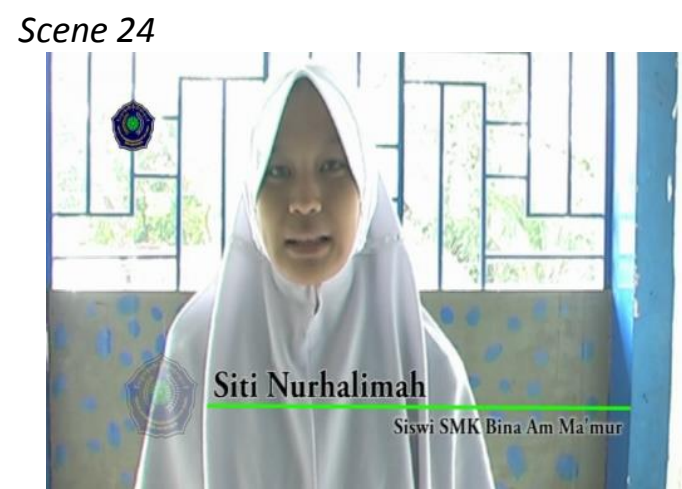

Gambar 29. Video Wawancara siswi SMK Bina Am Ma'mur

Medium Close Up (MCU) / INT

Menggambarkan Wawancara siswi SMK Bina Am Ma'mur
Scene 25

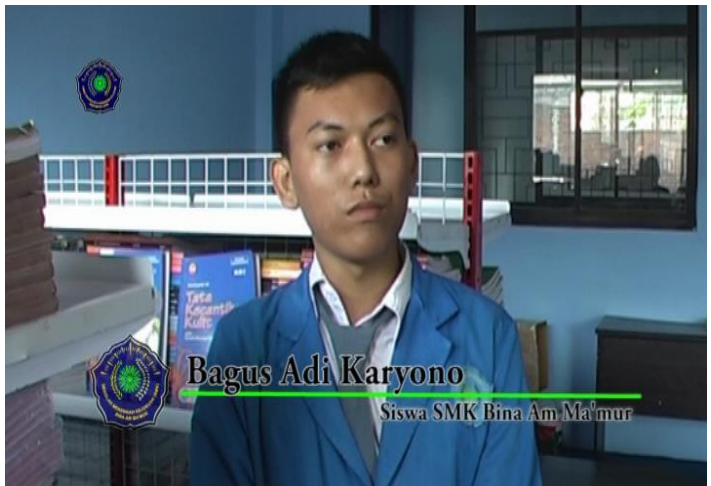

Gambar 30. Video Wawancara siswa SMK Bina Am Ma'mur/ Medium Close Up

Medium Close Up (MCU) / INT

Menggambarkan Wawancara Siswa SMK Bina Am Ma'mur

Scene 26

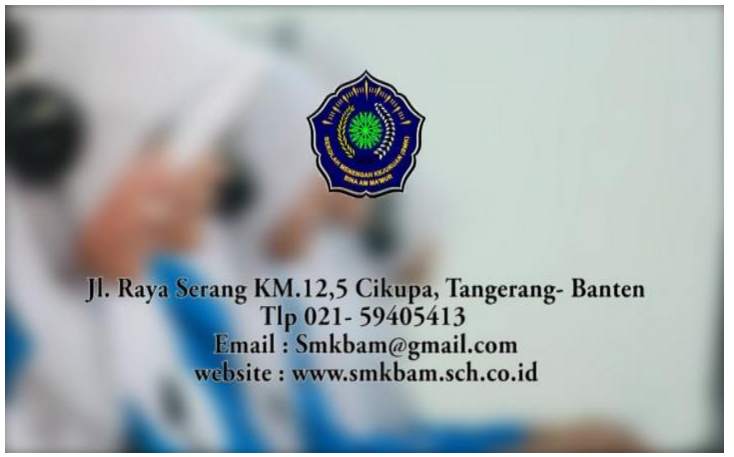

Gambar 31. Video Bumper Akhir Logo Sekolah Berikut Alamat Lengkap

Menggambarkan Bumper akhir logo sekolah dan alamat lengkap SMK Bina Am Ma'mur

\section{Setting Alat}

Dalam pembuatan video profile menggunakan alat Camera, Tripod, Slider dan Microphone. Untuk Camera yang digunakan penulis menggunakan Camera DSLR Canon 60D. Dalam Video audio visual ini banyak digunakan dilokasi dalam kantor. Sedangkan pengambilan suara untuk wawancara menggunakan Mic Pro Kenwood KW321 


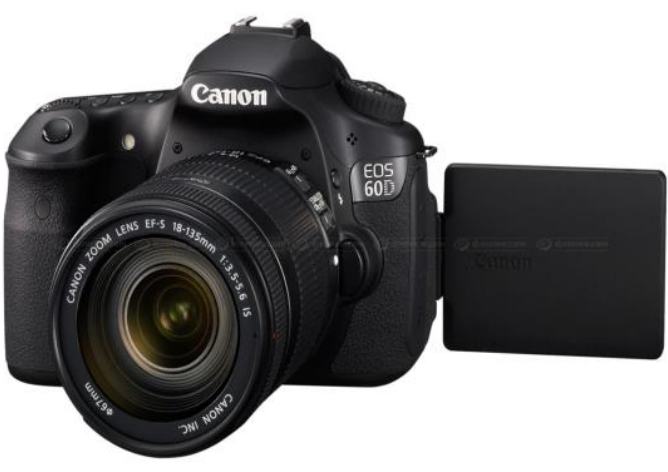

Gambar 32. Kamera DSLR Canon 60D

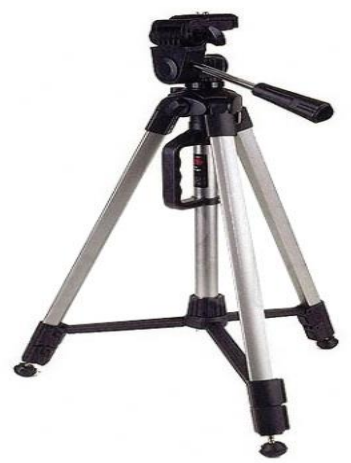

Gambar 33. Tripod kamera

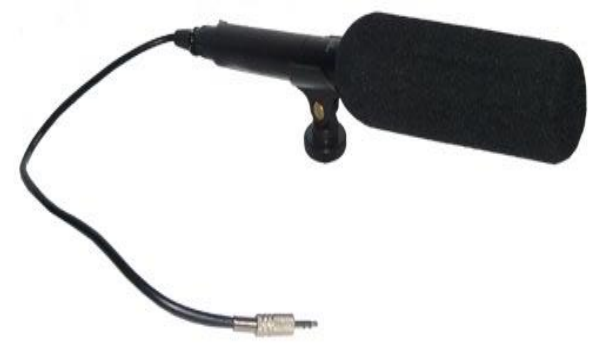

Gambar 34. microfon Shotgun

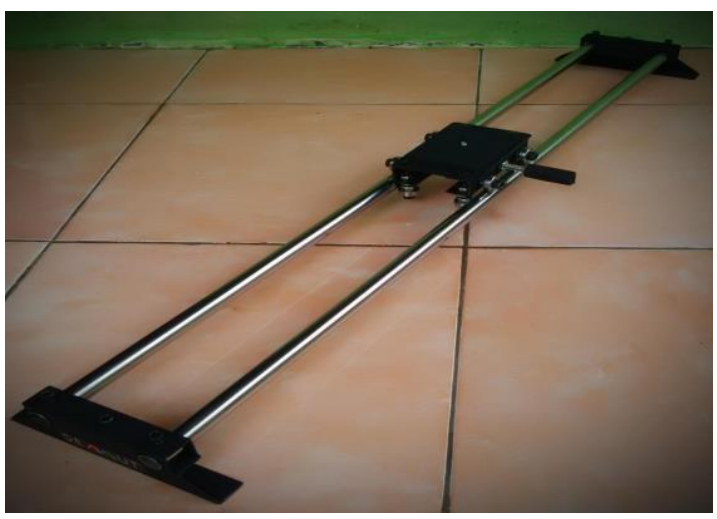

Gambar 35. Slider

\section{Production}

Production adalah proses pengambilan gambar atau shooting video dengan bekerjasamanya antara pemain dan crew untuk pewujudan rumusan dari tahap preproduction dalam bentuk skenario, naskah, dan storyboard yang telah dibuat.

\section{Strategi Multimedia}

Geografi : Wilayah Kabupaten dan Kota Tangerang

Demografi:

- Jenis Kelamin : Pria \& Wanita

- Usia : 13 s/d 16 tahun

- Kelas Ekonomi :Menengah Atas Menengah Bawah

- Sasaran :1.Siswa-siswi SMP / Setara 2.Relasi dari Sekolah tertentu 3.Transfer atau pindahan

Psikografi : Siswa siswi Sekolah Menengah Pertama (SMP) atau Setara dengan SMP, siswa-siswi transfer, relasi dan masyarakat umumnya khususnya di daerah kota Tangerang dan Kabupaten Tangerang untuk mengetahui informasi lebih detail tentang SMK Bina Am' Makmur Tangerang dan yang ingin melajutkan pendidikan di Sekolah Menengah Kejuruan.

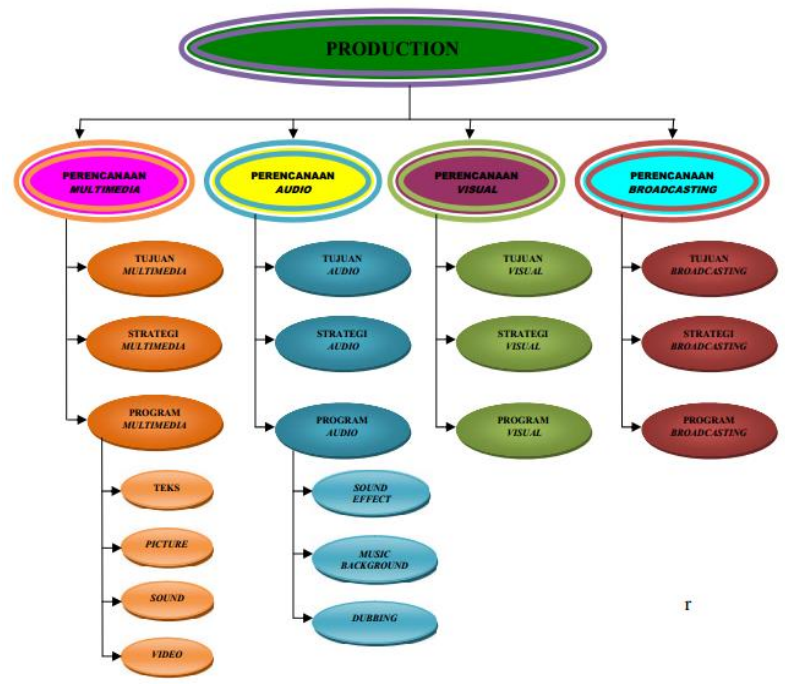

Gambar 36. Production 


\section{Postproduction}

Tahap postproduction adalah proses finishing sebuah karya sampai menjadi sebuah video yang utuh dan mampu menyampaikan sebuah cerita atau pesan kepada audience. Dalam proses postproduction semua gambar yang didapat pada proses production di satukan dan di edit oleh seorang editor.

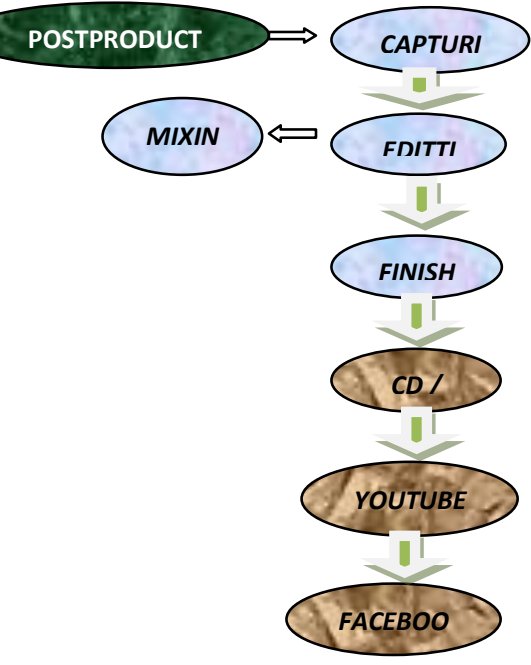

Gambar 37. Postproduction

\section{KESIMPULAN}

Media video profile dapat bernilai positif bagi masyarakat, karena banyak hal baik yang bisa langsung dilihat oleh masyarakat khususnya orang tua dari calon murid SMK Bina Am' Makmur, seperti kegiatan sekolah yang ada, fasilitas yang ada di sekolah, sehingga membuat orang tua tidak ragu menyekolahkan anaknya di SMK Bina Am' Makmur. Dengan desain yang menarik dihapkan dapat memberikan minat pada calon siswa/i SMK Bina Am' Makmur.

\section{DAFTAR PUSTAKA}

[1] Arifin, Eva. 2010. Broadcasting To Be Broadcaster, Yogyakarta : Graha Ilmu.
[2] Atmohoetomo 2010. Media Audio Visual Pendidikan dan Proses Produksi Programnya. Yogyakarta: Pusdiklat Perpustakaan IKIP.

[3] Ayuningtyas, Melvy. 2011.Ngedit Video Dengan Adobe Premiere CS3, Yogyakarta, Dunia Komputer.

[4] Binanto, Iwan. 2010. "Multimedia Digital Dasar (Teori dan Pengembangannya)", Yogyakarta: Andi

[5] Dewi, Sudaryono, Dwi Ayu Ningrum, Enriching Media Merchandise Sarana Penunjang Promosi Studi Kasus Pada BookStore. dalam jurnal CCIT vol. 7, No.3, 2014.

[6] Kusrini. 2010. Sistem Pakar Teori Dan Aplikasi. Yogyakarta: Andi.

[7] Kuswandi, Wawan, 2011.Komunikasi Massa Sebuah Analisis Media Televisi, Jakarta, Rineka Cipta.

[8] Maimunah, Lusyani Sunarya dan Nina Larasanti, 2012 "Media Company Profile Sebagai Sarana Penunjang Informasi dan Promosi" Tangerang Jurnal CCIT Vol.5 No.3

[9] Purnomo, Adi, Sonny. 2011. Perancangan Video Profil Wave Production. Jakarta, Rineka Cipta

[10] Supriyono, Rakhmat. Desain Komunikasi Visual Teori dan Aplikasi, Yogyakarta : Andi, 2010.

[11] Wibowo, Ibnu Teguh. 2013. Belajar Desain Grafis. Jakarta: Grasindo. 